\title{
PRESERVAÇÃO DAS ÁGUAS NO MEIO RURAL E UTILIZAÇÃO DE RECURSOS DIDÁTICOS PARA SENSIBILIZAÇÃO AMBIENTAL: UMA PROPOSTA PARA EDUCADORES AMBIENTAIS.
}

\author{
Fabiane Malakowski de Almeida Wentz \\ Química Licenciada . Especialista em Educação Ambiental pela Universidade Federal de Santa Maria \\ Endereço(1): Avenida Brasil, 102. CEP: 98801-590. Santo Ângelo - RS. Brasil - Tel: (55) 9913-0826 - e-mail: \\ fabiane.m.almeida@bol.com.br
}

\section{RESUMO}

Um dos principais problemas enfrentados pela população brasileira é a falta de saneamento e de cuidados com a qualidade das águas, principalmente no meio rural, onde não existe controle sistemático e permanente da qualidade da água oferecida à população e, aparentemente, só existe tomada de atitude quando aparece algum problema de saúde na comunidade. $\mathrm{O}$ aumento da poluição ambiental ocasionado pelas novas fontes pontuais e difusas de poluição geram a necessidade de um controle mais eficiente desta qualidade, produzindo meios para o cumprimento da Portaria 518/04 do Ministério da Saúde e respeitando o direito constitucional ao abastecimento adequado de água. Este trabalho demonstra a situação existente em comunidades rurais da cidade de Santo Ângelo, denotando falta de cuidado na implantação dos poços e problemas de manutenção do sistema alternativo de abastecimento. A educação ambiental torna-se uma maneira de formação de conhecimentos nessas regiões em relação aos problemas ambientais, os cuidados, os direitos e deveres que se deve ter principalmente para a preservação das águas, tornando-se muito mais agradável ao olhar infantil por meio de atividades lúdicas como músicas, histórias em quadrinhos e teatro de fantoches.

Palavras - Chave: Saneamento, água potável, meio rural.

\section{ABSTRACT}

One of the main problems faced for the Brazilian population is the sanitation lack and of cares with the quality of waters, mainly in the agricultural way, where systematic and permanent control of the quality of the water offered to the population does not exist and, pparently, it only exists taken of attitude when it appears some problem of health in the community. The increase of the ambient pollution caused by the new prompt and diffuse sources of pollution generates the necessity of a more efficient control of this quality, producing half for the fulfilment of Portaria $518 / 04$ of the Health department and respecting the constitucional law to the adequate water supplying. This work demonstrates to the existing situation in agricultural communities of the city of Ângelo Saint, denoting lack of care in the implantation of the wells and problems of maintenance of the alternative system of supplying. Environmental education becomes a way of training knowledge in these areas in relation to environmental problems, care, rights and duties 
that must be primarily for the preservation of water, making it much more pleasing to look at children through recreational activities such as music, cartoons and puppet theater.

Keywords: Sanitation, drinking water, half rural, puppet theater.

\section{INTRODUÇÃO}

A água é o constituinte inorgânico mais abundante na matéria livre, algumas avaliações indicam possuir uma distribuição de água no planeta de 1360 quatrilhões de toneladas, porém desta apenas $0,8 \%$ pode ser utilizada para o abastecimento público, e destes $97 \%$ são águas subterrâneas e apenas 3\% apresentam-se na forma de água superficial, isto nos prova a grande importância de preservação destes recursos hídricos na terra e principalmente evitar a poluição da menor fração disponível que for (Barros et. al., 1995).

A poluição das águas cada vez mais é um fator de grande preocupação, os poluentes alcançam as águas superficiais e subterrâneas de diversas formas, principalmente por fontes difusas, que se espalham por inúmeros locais sendo difíceis de serem localizadas (Grassi, 2001).

O problema da diminuição da qualidade da água nos países em desenvolvimento necessita ser enfrentado. Nos dias atuais, nos deparamos com algumas áreas densamente povoadas com precárias condições de saneamento básico, sendo a água a principal responsável por um grande número de doenças de veiculação hídrica (Leser et. al., 1985).

A água recebida, geralmente na área rural, é proveniente de poços tubulares profundos, em um sistema coletivo, não provém de tratamentos (Barros et. al., 1995). As águas subterrâneas, potencialmente apresentam uma boa qualidade para o consumo humano, embora os lençóis estejam altamente sujeitos a contaminação e com fácil obtenção, não muitas vezes em quantidade suficiente. Geralmente nesses mananciais, a água sofre filtração natural pelas camadas do solo e possui uma grande contaminação por organismos patogênicos devido, principalmente, à proximidade de fossas, faltas de higiene no manuseio, entrada de água de chuvas, criação de animais próximos ao poço, que geralmente possui capacidade de atender uma família ou a um pequeno grupo de famílias (Grassi, 2001).

A captação das águas desses mananciais variam conforme as condições do local e se deve assegurar condições de fácil entrada da água em qualquer época do ano, assegurar tanto quanto possível a melhor qualidade do manancial e a segurança contra elementos tóxicos e inundações. Se acaso existir próximo ao local áreas de cultivo, deve ser vedado o uso de adubos de origem animal, produtos tóxicos que possam ser carreados para o sistema de abastecimento.

As doenças relacionadas com a água, e que afetam a saúde do homem, são muito difundidas e abundantes nas áreas rurais dos países em desenvolvimento e sua incidência depende de diversos fatores, dentre eles a distribuição, a quantidade e qualidade da água de abastecimento (Schiavetti et al. 2002). Ocorre os surtos de doenças de veiculação hídrica, principalmente em função da possibilidade de contaminação bacteriana de águas que muitas vezes são captadas em poços velhos, inadequadamente vedados e próximos de fontes de contaminação, como fossas e áreas de pastagem ocupadas por animais (Stukel et al, 1990 apud Amaral; Filho, 2003).

A parcela de água existente no planeta utilizável para o consumo humano é muito pequena, existem vários tipos de mananciais para o abastecimento público, destacaremos o 
manancial subterrâneo, cuja água vem do subsolo, podendo aflorar a superfície ou ser elevado através de obras de captação, esses são normalmente utilizáveis pelas localidades interioranas. Esse tipo de reserva pode provir de dois tipos de lençóis aqüífero, onde a água se encontra livre com sua superfície sob a ação da pressão atmosférica é conhecido como lençol freático. Já, onde a água encontra-se confinada em camadas impermeáveis e sujeita a uma pressão maior que a pressão atmosférica é conhecido como lençol confinado (Barros et al. , 1995).

A água subterrânea, além de ser um bem econômico, é considerada mundialmente uma fonte imprescindível de abastecimento para consumo humano, para as populações que não têm acesso à rede pública de abastecimento ou para aqueles que, tendo acesso a uma rede de abastecimento, têm o fornecimento com freqüência irregular. No Brasil, o aqüífero subterrâneo abastece 6.549 .363 domicílios (19\% do total), e, destes, $68,78 \%$ estão localizados na área rural, abrangendo $11,94 \%$ de toda a população nacional (IBGE, 1994).

Toda a água destinada ao consumo humano deve obedecer ao padrão de potabilidade e está sujeita à vigilância da qualidade da água, os parâmetros microbiológicos, físicos, químicos e radioativos devem atender ao padrão e que não ofereça riscos à saúde (PORTARIA № 518/GM, 2004).

A secretaria municipal de saúde e seus responsáveis devem fornecer a todos os consumidores, nos termos do Código de Defesa do Consumidor, informações sobre a qualidade da água distribuída, mediante envio de relatório, dentre outros mecanismos, com periodicidade mínima anual e contendo, no mínimo, as seguintes informações: descrição dos mananciais de abastecimento, incluindo informações sobre sua proteção, disponibilidade e qualidade da água, estatística descritiva dos valores de parâmetros de qualidade detectados na água, seu significado, origem e efeitos sobre a saúde e ocorrência de não conformidades com o padrão de potabilidade e as medidas corretivas providenciadas (PORTARIA № 518/GM, 2004).

A maioria das doenças nas áreas rurais podem ser consideravelmente reduzidas, desde que a população tenha acesso a água potável. Entretanto, um dos maiores problemas das fontes particulares é a ausência de monitoramento da qualidade da água consumida (Misra, 1975 apud Amaral Filho; et al., 2003).

É direito de toda a população, ter acesso a uma água de boa qualidade. As autoridades de saúde pública devem estabelecer entendimentos para a elaboração de um plano de ação e tomada das medidas cabíveis, incluindo a eficaz comunicação à população, sem prejuízo das providências imediatas para a correção da anormalidade quando detectada (PORTARIA № 518/GM, 2004). O uso sustentável da água é vital para a nossa sobrevivência no futuro, no entanto é necessário, uma mudança drástica no comportamento frente ao seu uso, se quisermos possuir de água de qualidade e adequada para o consumo (Grassi, 2001).

A Educação Ambiental, possui o objetivo de sensibilizar e informar a comunidade sobre os temas de saneamento, saúde e ambiente, abordando-os sob a ótica da promoção da saúde e melhoria das condições ambientais e da qualidade de vida. (Ribeiro; Günther, 2003).É um processo de aprendizagem permanente, baseado em todas as formas de vida, afirma valores e ações que contribuem para a transformação humana e social, bem como a preservação ecológica. Estimula ainda, a formação de sociedades socialmente justas e ecologicamente equilibradas, que conservem entre si relações de independência e diversidade. (Marcatto, 2002)

O Saneamento possui uma importância em relação a preservação da qualidade ambiental do município, é necessário que o mesmo faça parte das diretrizes ambientais, como se sabe, ainda, a insuficiência ou a falta de saneamento constitui em uma das maiores fontes de poluição, degradando o ambiente muitas vezes quase irreversivelmente. 
O saneamento ambiental não tem sido historicamente priorizado, seja na formulação de políticas públicas ou nas ações do setor privado da economia, resultando em condições insatisfatórias, que decorrem da sua insuficiência ou deficiência. Esse fato é agravado pela falta de informação da população para enfrentar as condições sanitárias precárias vividas, aliando-se à falta de incorporação de hábitos e práticas sanitárias e ambientais em seu quotidiano. (Ribeiro; Günther, 2003)

Porém, as ações de saneamento ambiental e promoção da saúde, levadas como atividades fins, não são suficientes se não houver participação comunitária/institucional no direcionamento, implementação e na sustentabilidade de tais ações. Através da mobilização da população, pode-se buscar soluções viáveis para os problemas de saneamento ambiental, visando resultados positivos, benefícios, e uma eficiente política de gestão pública dos serviços de saneamento básico. (Medina, 1999).

Assim sendo, integrando o conhecimento sistematizado e as realidades sociais envolvidas, leva-se a um processo de sensibilização, comprometimento e consciência ambiental, com ênfase na aprendizagem sobre o tema tratado, permitindo o desenvolvimento de competências: análise, decisão, planejamento e pesquisa, exercendo assim a cidadania. E ainda traz-se o acesso da população a informações sobre o tema e o estímulo à organização e participação na busca das resoluções dos problemas vivenciados cotidianamente, ainda mudanças de atitudes e comportamentos, em favor de melhorias nas condições de saúde, qualidade de vida e reflexos positivos no meio ambiente e seu entorno. Ainda, utilizando o Saneamento Ambiental nos conteúdos baseados na Educação Ambiental a proposta apresentará sucesso e modificará o panorama sanitário-ambiental dos municípios, e ainda, contribui para as informações dos cidadãos melhorando as condições ambientais e a qualidade de vida dos moradores e promovendo a saúde pública. (Ribeiro; Günther, 2003)

Através da educação ambiental, o indivíduo e a coletividade constroem valores sociais, conhecimentos, atitudes, habilidades, interesse ativo e competência, voltados ao meio ambiente. Ainda que de natureza recente enquanto uma área delimitada do saber e sob essa denominação, a educação ambiental contribui para a sociedade como um todo, em termos de reflexões, indagações, sensibilizações, discussões, ações e avaliações, pertinentes à temática sócioambiental. E acima de tudo, é um processo contínuo de reflexão e ação do ser humano no ambiente, com o ambiente e para o ambiente, promovido pela prática educativa, coletiva ou individualmente construída. É um ramo da educação que marca a história e redefine os rumos da humanidade e do planeta, resgatando valores de cidadania para o respeito. (Medina, 1999). Além de incentivar à participação individual e coletiva, permanente e responsável, na preservação do equilíbrio do meio ambiente, entendende-se a defesa da qualidade ambiental como um valor inseparável do exercício da cidadania. Com um pouco de boa vontade, tanto dos educadores como da população, a educação ambiental pode trazer bons resultados. (Marcatto, 2002).

Este trabalho retrata a situação de três comunidades rurais do município de Santo Ângelo -RS, no que tange a qualidade do sistema alternativo de abastecimento de água e formação da sensibilização ambiental para o cuidado com a preservação das águas.

\section{MATERIAL E MÉTODO}

Este trabalho foi desenvolvido em três etapas, inicialmente realizou-se uma pesquisa de campo, para conhecer as três comunidades rurais. Logo após foram coletados dados dos poços 
junto à Administração Municipal de Santo Ângelo, através da Secretaria de Agricultura, responsável pela estrutura dos poços, verificada a localização e o controle da qualidade dos mesmos, podendo-se constatar com detalhe a atual situação da qualidade das águas nessas localidades.

A segunda etapa foi constituída pela identificação e caracterização dos poços, bem como as condições de saneamento local e do entorno destes sistemas de abastecimento, por meio de uma pesquisa de campo realizada entre os moradores das três localidades.

E por fim, levou-se atividades de sensibilização ambiental para estas comunidades por meio da educação ambiental, promovida utilizando diferentes recursos que contribuíram para a explanação dos resultados, conhecimento da legislação dos direitos e deveres em relação a preservação das águas e formação da cidadania ambiental.

\section{RESULTADOS E DISCUSSÕES}

Observou-se os poços principais das três localidades, todos pertencentes ao sistema alternativo de abastecimento destas comunidades. Notou-se que o poço 1 está localizado em um nível acima da estrada de acesso principal, próximo ao Arroio do Meio e em um nível abaixo das construções. O local é cercado, estando localizado em um potreiro, conforme apresentado abaixo.

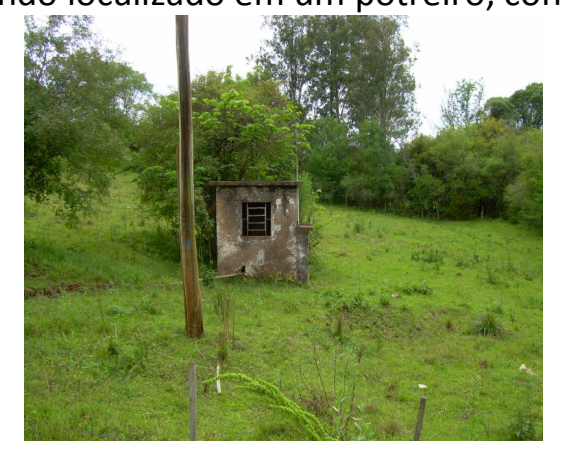

Figura1: Situação do Poço 1

O poço 2, possui uma situação muito crítica, pois está localizado junto ao pátio de um Posto de Saúde da comunidade, ao lado da Escola e próximo à estrada que dá acesso principal à comunidade, em um nível mais baixo do terreno. Logo foram constatadas possíveis contaminações neste sistema de abastecimento pela colocação de herbicidas e outros insumos da lavoura, próximo ao local, sem cuidado com o sistema de abastecimento. Logo abaixo, aproximadamente, $3 \mathrm{~m}$ a construção da Escola e a uns $10 \mathrm{~m}$ se situa a horta escolar com diferentes tipos de hortaliças produzidas para a merenda escolar, estando exposto a diferentes tipos de contaminação oriundas dos esgotos, fossas e demais lixos gerados por essas construções. No poço não existe nenhuma proteção, está coberto pela vegetação e aberto.

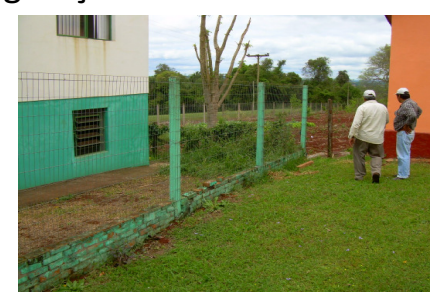

figura 2: Poço 2 entre Escola (laranja) e o Posto de Saúde ( branco). 
O poço identificado como 3, da mesma forma que os anteriores, apresentou localização inadequada, falta de proteção e próximo a construções. A figura 3 mostra a localização do poço no terreno e um momento durante a coleta. Observa-se também a falta de proteção do manancial, de fácil acesso e com canalizações expostas.

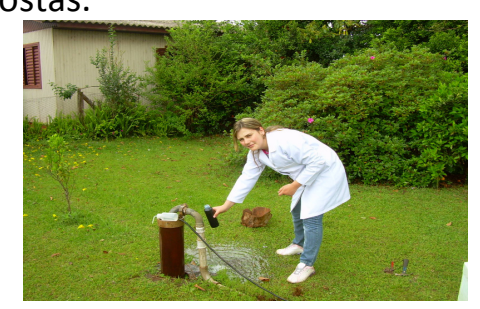

Figura 3: Identificação do Poço 3 .

Obervou-se que os três poços apresentavam padrões sanitários incorretos, percebendose que não foram seguidos os padrões definidos pelo Ministério da Saúde para preservar a qualidade da água desses mananciais, estando os aqüíferos expostos aos impactos da extração descontrolada e da ocupação indisciplinada do solo, que põem em risco a qualidade das águas subterrâneas, especialmente, neste caso.

Realizou-se a pesquisa de campo junto aos moradores das três localidades, distribuídos entre $30 \%$ dos entrevistados na comunidade do poço 1, 30\% dos entrevistados na comunidade do poço 2 e $40 \%$ dos entrevistados na comunidade do poço 3, por se tratar da comunidade que possui maior número de habitantes. Verificou-se que a maioria já encontrou algum tipo de característica indesejável na água com $47 \%$ dos entrevistados percebendo alteração de cor, $35 \%$ detectaram alteração de sabor e 18 \% informaram a presença de sólido. Estima-se que a causa dessas alterações seja devido a infiltrações que ocorrem nos poços de abastecimento, principalmente em épocas de muitas chuvas, segundo citação oral dos entrevistados.

Ainda houve a confirmação de que a principal fonte de abastecimento de água, pelos moradores da região, é feita pelos poços tubulares profundos, totalizando $83 \%$ dos entrevistados, $11 \%$ possuem abastecimento por água superficial e $6 \%$ direto da nascente, $3 \%$ desses casos possuem as duas formas de abastecimento. É necessário que haja uma conscientização das pessoas que utilizam fontes não seguras, principalmente, não existindo nenhum tipo de tratamento, uma vez que essas fontes estão mais sujeitas a diferentes tipos de contaminação por estarem expostas sem nenhuma proteção.

Pode-se verificar que nessas localidades, os principais usos da água são para o consumo humano, lavar louça, lavar roupa, banho e mais da metade para irrigação, dessedentação dos animais e um pouco menos da metade para a diluição de agroquímicos e limpeza das instalações rurais. Neste caso, foi recomendado aos moradores que utilizem diferentes formas de reaproveitamento de água, para utilização na irrigação, diluição de agroquímicos e limpezas em geral, como por exemplo, o uso de cisternas, através da captação das águas das chuvas. Esta situação da pesquisa encaminha para uma nova posição a ser adotada pela Administração Pública Municipal, no sentido de privilegiar este tipo de solução que possibilita uma nova dimensão do uso da água, racionalizando seu emprego e permitindo que as novas gerações não venham a ter uma água com qualidade comprometida e/ou em quantidade deficiente.

Nestas localidades identificou-se que a maioria dos entrevistados pratica atividades de racionamento, sendo que $94,3 \%$ colocou que pratica alguma ação para o uso racional da água e $5,7 \%$ que não pratica este tipo de ação. A maioria dos entrevistados está consciente em relação 
ao desperdício com torneiras abertas, vazamentos e banhos prolongados, porém um percentual muito baixo em relação ao número de entrevistados preocupa-se em recolher água da chuva ou utilizar formas de reaproveitamento da água. A sociedade brasileira e o Poder Público devem sensibilizar-se para a problemática da gestão adequada dos recursos hídricos sendo necessário uma ação efetiva que leve à população a conscientização, permitindo novas posturas, a médio e longo prazo, de forma a racionalizar o uso da água. Para isto são necessárias políticas públicas adequadas e comprometidas, pois leis existem em quantidade e com qualidade suficiente, mas é inadequada a interface entre as Políticas públicas e a população geradora e última determinantes de novos comportamentos, sem os quais nada muda, a nível deste insumo natural e econômico da comunidade brasileira, especialmente.

Quanto a presença de doenças de origem hídrica já observadas na residência ou na localidade, $85 \%$ dos entrevistados não identificaram alguma doença causada, diretamente, pela água, apenas $7 \%$ perceberam este tipo de problema. 0 interessante é que este último percentual coincidiu com pessoas de maior nível cultural, o que nos remete à preocupação se de fato não ocorreram estas doenças, ou se os entrevistados, pela sua menor cultura não ligaram a causa ao efeito. De acordo com a Secretaria de Agricultura do município, 95\% dos poços do interior, são poços ilegais e não está de acordo com as normas de perfuração e estruturação dos poços, não existindo nenhuma forma de tratamento das águas destes mananciais, o controle, em geral, é feito no caso de ser detectada alguma irregularidade no mesmo. Neste aspecto é reforçada a percepção de urgência no investimento em setores como o de saneamento e na administração dos recursos hídricos, além do estabelecimento de áreas adequadas para as atividades com maior risco de degradação dos aqüíferos, priorizando a aplicação de recursos técnicos e financeiros para a implantação de poços com a infra-estrutura adequada ao cumprimento da Portaria 518/2004, em respeito ao direito destes cidadãos.

Através da educação sanitária e ambiental promovida na escola, pode-se manter a comunidade informada sobre os conceitos de meio ambiente, o que fazemos e o que podemos tentar mudar nas nossas atividades diárias para a preservação do meio ambiente. Mostraram-se seus direitos e deveres em relação as questões de saneamento e meio ambiente, apresentou-se os resultados da pesquisa e as fotos retiradas nas comunidades interioranas, mostrando seus problemas e situação atual e o que pode ser feito para melhorar.

Para Silva (2008), "deve-se trabalhar na escola a educação Ambiental não por ser uma exigência do Ministério da Educação, mas porque acredita ser a única forma de aprender que os seres humanos, não são os únicos habitantes deste planeta, que não possuem o direito de destruílo, pois da mesma forma que herdamos a terra de nossos pais, deveremos deixá-la para nossos filhos".

Utilizaram-se diferentes recursos pedagógicos para este trabalho, tais como músicas, histórias em quadrinhos, formulados por sites da internet da "Turma da Mônica" e o Hagaquê. Utilização de fantoches para a explanação da sensibilização por meio de teatro, utilizando sons, músicas, imagens e alegria para as crianças de 1a a 4 a ano do ensino fundamental.

Pode-se perceber através da reação dos alunos um grande efeito positivo na utilização dos fantoches para promoção da sensibilização, por meio do teatro "Amigos da Água" apresentado com fantoches, notou-se a atenção, interesse e alegria nos rostos das crianças assimilando melhor o conhecimento sobre o tema.

Pode-se identificar que muitos nem haviam percebido a importância que se deve ter com os cuidados em relação aos tipos de fatores que causam a contaminação das águas; 
Pode-se perceber um grande entusiasmo dos alunos, em reeducar seus hábitos em apresentar suas experiências já vividas, os alunos sentiram-se motivados e pode-se deixar mensagens de conscientização através das músicas, palavras, figuras e historinhas que ficaram marcadas nas suas memórias.

O trabalho com Educação Ambiental deve ser altamente crítico e reflexivo, levando todos os envolvidos a mudar de atitudes que levam a degradação do planeta Terra. De acordo com Encarnação (1997) apud Silva (2008), a educação ambiental deve ser entendida como uma prática social transformadora da sociedade que deve-se preocupar com o patrimônio natural através de uma consciência ambiental. Ao mesmo tempo a educação sanitária possibilita um novo foco que agrega percepção do ambiente, as questões de saneamento básico, propiciando uma discussão que agrega a situação concreta de saúde do homem, vivenciando novas formas de abordagem.

Quando nos referimos à educação ambiental, situamo-na em contexto mais amplo, o da educação para a cidadania, configurando-a como elemento determinante para a consolidação de sujeitos cidadãos. O desafio do fortalecimento da cidadania para a população como um todo, e não para um grupo restrito, concretiza-se pela possibilidade de cada pessoa ser portadora de direitos e deveres, e de se converter, portanto, em ator co-responsável na defesa da qualidade de vida. O principal eixo de atuação da educação ambiental deve buscar, acima de tudo, a solidariedade, a igualdade e o respeito à diferença através de formas democráticas de atuação baseadas em práticas interativas e dialógicas. Isto se consubstancia no objetivo de criar novas atitudes e comportamentos diante do consumo na nossa sociedade e de estimular a mudança de valores individuais e coletivos (Jacobi, 1997).

Com certeza, o trabalho foi desenvolvido de forma clara, reflexiva e crítica, acreditandose que todos, inclusive os que estavam mais dispersos levaram alguma mensagem que poderão originar novas atitudes, mesmo que pequenas, pois são elas que fazem a diferença e com o apoio da prefeitura e comitê ljuí, este trabalho será levado a outras comunidades que também precisam do mesmo em suas atividades diárias.

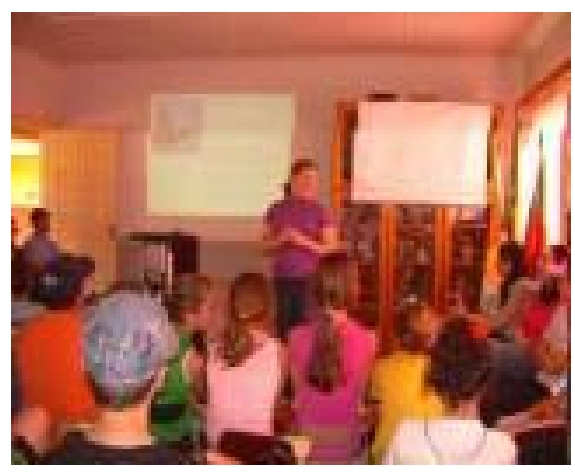

Figura 4 - Atividade de Educação Ambiental 


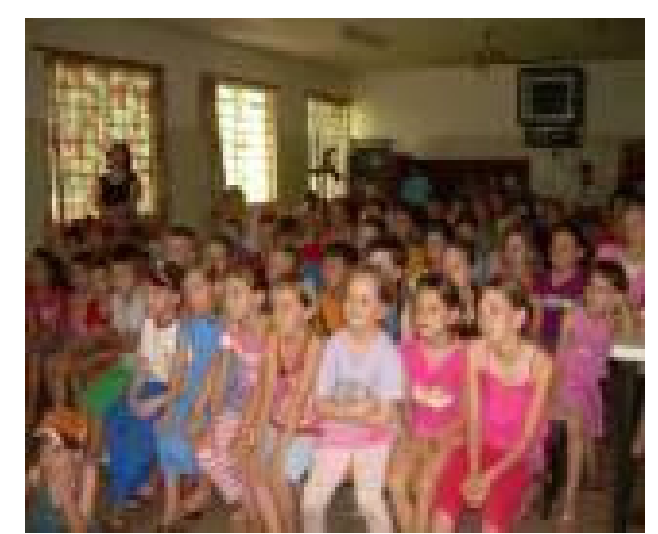

Figura 5 - Atividade de Educação Ambiental realizada Para os alunos do Ensino Fundamental da Escola Buriti.

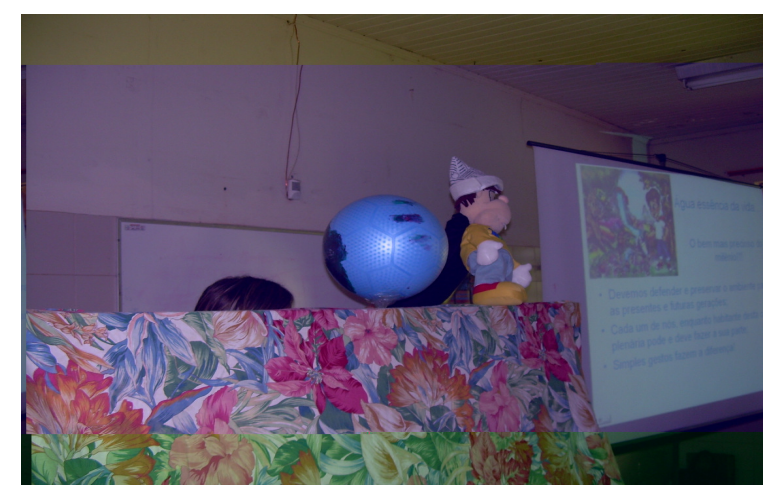

Figura 6- Atividade de Educação Ambiental com fantoches Alunos da Educação Infantil e Séries Iniciais

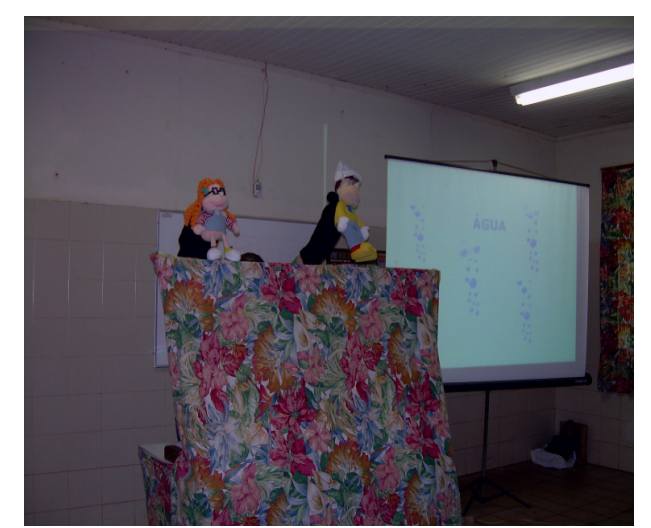

Figura 6- Atividade de Educação Ambiental com fantoches Alunos da Educação Infantil e Séries Iniciais

Do ponto de vista da educação ambiental, uma das grandes contribuições que podemos citar é que um dos papéis mais importantes da escola é que ela contribua para que as crianças cresçam na vivência de valores e não apenas na sua aceitação e/ou aprendizagem, até porque não se ensinam valores. Há que vivê-los e de preferência, em comunidade. (Barcelos, 2010). 
Desta forma, a educação ambiental serve além de muitas atividades, para a construção de valores culturais e ambientais para o desenvolvimento e formação do cidadão sensibilizado e comprometido com o meio ambiente.

\section{CONCLUSÕES}

Comprovou-se a falta de cuidados dos moradores e da Administração Pública com os recursos hídricos e saneamento para o meio rural, uma vez que foram encontrados poços mal localizados, não protegidos e isolados, sem cumprimento dos preceitos legais. O risco à saúde pública está presente nestes locais e se faz necessário conscientização da população, a busca dos seus direitos e mesmo a implantação de cuidados simples como limpeza da caixa de água, uso de pequenas quantidades de hipoclorito na água, fervura da água para consumo, formas que podem melhorar esta situação, até que sejam cumpridos os direitos destas comunidades, no que diz respeito ao direito a água potável

Através da educação sanitária e ambiental promovida, pode-se manter a comunidade informada sobre os cuidados, racionamento e outros, ainda, promover a sensibilização ambiental motivadora com recursos pedagógicos que atraem principalmente as crianças.

Enfim, a educação ambiental é um tema muito importante e que deve ser trabalhada resgatando valores, culturas e hábitos na questões ambientais que podem mudar ou retardar a atual crise ambiental que presenciamos e a que prevemos. Se os órgãos públicos responsáveis e comunidades trabalharem juntas, com certeza teremos um interior mais rico, mais saudável e ambientalmente sustentável.

\section{REFERÊNCIAS BIBLIOGRÁFICAS}

Almeida, Fabiane M. de; SANTOS Zuleica Souza dos. A Qualidade da Água para o Abastecimento Público no Meio Rural e Ações de Controle da Qualidade dos Mananciais e Prevenção de Doenças de Origem Hídrica. Santo Ângelo: URI, 2009. Trabalho de Conclusão de Curso (TCC), Departamento de Ciências Exatas e da Terra, Universidade Regional Integrada, 2009. 65p.

AMARAL, L. A. do; FILHO, A. N.; JUNIOR, O. D. R.; FERREIRA, F. L. A.; BARROS, L. S. S. B. Água de consumo humano como fator de risco à saúde em propriedades rurais. Revista de Saúde Pública, São Paulo. vol. 37, n. 4. ago. 2003. Disponível em: <http://www.scielosp.org>. Acesso em: 18 de mai. de 2010.

AMBIENTEBRASIL. Educação Ambiental. Em $<$ http://www.ambientebrasil.com.br/composer.php3?base=./educacao/index.php3\&contudo=./educacao/ educacao.html>; acesso em 03/06/11.

BARROS, Raphael T. de V. et alli. Saneamento. Manual de Saneamento e Proteção Ambiental para os Municípios. Volume 2. Belo Horizonte: Escola de Engenharia da UFMG, 1995. 221p.

BERNA, V. (2001). Como fazer a educação ambiental. São Paulo. Annablume. 
BRASIL, 2004 . Portaria 518. Estabelece os procedimentos e responsabilidades relativos ao controle e vigilância da qualidade da água para consumo humano e seu padrão de potabilidade, e dá outras providências. Ministério da Saúde, Secretaria de Vigilância em Saúde, Coordenação- Geral de Vigilância em Saúde Ambiental - Brasília: Diário Oficial da União, 2005.

BRASIL. Secretaria de Educação Fundamental. Parâmetros Curriculares Nacionais: Meio Ambiente, Saúde. Brasília: MEC/SEF, 1997.

CHAVES, Adilson de. Diagnóstico das Águas Subterrâneas no Município de São Luiz Gonzaga/RS. Santa Maria: UFSM, 2007. Trabalho de Graduação (Monografia), Centro de Ciências Naturais e Exatas. Departamento de Geociências, Universidade Federal de Santa Maria, 2007. 121p.

GELDREICH, E.E. Aspectos microbiológicos dos esgotos e dos seus processos de tratamento. In: Secretaria dos Serviços e Obras Públicas. Desinfecção das águas. São Paulo: CETESB, 1974.

GRASSI, Marco Tadeu. As Águas do Planeta Terra. Caderno Temático de Química Nova na Escola. Ed. Especial. n.1, p.31-40. Mai.2001. Disponível em: <http://qnesc.sbq.org.br/online/cadernos/01/aguas.pdf > . Acesso em: 06 mai. 2010.

IBGE (Fundação Instituto Brasileiro de Geografia e Estatística), 2011. Primeiros resultados do censo 2010. Disponível: www.ibge.gov. Acesso em 15 maio de 2011.

IBGE (Fundação Instituto Brasileiro de Geografia e Estatística), 1994. Dados sobre Domicílios no Estado do Rio de Janeiro. Anuário Estatístico do Brasil, v. 54. Rio de

Janeiro: IBGE.

JACOBI, P. et al. (orgs.). Educação, meio ambiente e cidadania: reflexões e experiências. São Paulo: SMA, 1997.

JORNAL DAS MISSÕES. Agricultura e Transportes - Qualidade de Vida no Interior. Santo Ângelo, 24/03/2007.

LEMOS, Carolina Alves; GUERRA, Teresinha. Aspectos dos Usos da Água, Agrotóxicos e Percepção ambiental no Meio rural, Maquiné, RS, Brasil. Programa de Pós-Graduação em Ecologia - Instituto de Biociências - UFRGS. Volume 13 . n.2. Jul/Dez. 2004. Disponível em http://www.geo.uel.br/revista. 103. Acesso em 15 de abril de 2010.

LESER, W. S.; BARBOSA, V.; BARUZZI, R. G.; RIBEIRO, M. D. B. \& FRANCO, L.J.Elementos de Epidemiologia Geral. São Paulo: Atheneu, 1985.

MAQUINA DE QUADRINHOS. Turma Da Mônica. Disponível em: http://www.maquinadequadrinhos.com.br/Privado/MeusQuadrinhos.aspx. Acesso em: 06 de maio de 2011.

MARCATTO, Celso. Educação ambiental: conceitos e princípios. Belo Horizonte: FEAM, 2002.

MEDINA, Naná M. Formação de Multiplicadores para Educação Sanitária e Ambiental. In: Revista Eletrônica do Mestrado em Educação sanitária e Ambiental - FURG. Vol. 1., Out. - Dez/1999. 
NASCIMENTO, Nilo de O; HELLER, Léo. Ciência, Tecnologia e Inovação na Interface entre as Ares de Recursos Hídricos e Saneamento. Engenharia Sanitária e Ambiental. Minas Gerais, Vol.10 - № 1, p 3648, jan/mar 2005.

PÁDUA, S.; TABANEZ, M. (orgs.). Educação ambiental: caminhos trilhados no Brasil. São Paulo: Ipê, 1998.

RIBEIRO, Helena; GÜINTER, Wanda M. R. Integração entre a Educação Ambiental e o Saneamento Ambiental como Estratégia para a Promoção da Saúde e do Meio Ambiente Sustentado. Faculdade Saúde Pública-Univ. São Paulo, Departamento de Saúde Ambiental. São Paulo, 2002. Disponível em www.bvssp.fsp.usp.br/tecom/docs/2003/rib001.pdf. Acesso em 20 mai. 2010.

RUY, R. A. V. A Educação Ambiental na Escola. In: Revista Eletrônica de Ciências. №26, Mai, 2004.

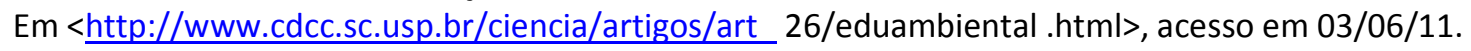

SARDINHA, Diego. Et.al. Avaliação da qualidade da água e autodepuração do ribeirão do meio, Leme (SP). Engenharia Sanitária e Ambiental. São Paulo, Vol.13 - № 3, p 329-338, jul/set 2008.

SCHIAVETTI, A., SCHILLING, A. C. E OLIVEIRA, H. T. 2002. Caracterização sócio-ambiental da bacia hidrográfica do rio Cachoeira, sul da Bahia, Brasil. In: SCHIIAVETTI, A. e CAMARGO, A. F. M. Conceitos de bacias hidrográficas: teorias e aplicações. Ilhéus: Editus, 141-162pp.

SILVA, Andréia Cristina Souza e. O Trabalho de Educação Ambiental em Escolas de Ensino Fundamental. Revista Eletrônica do Mestrado em Educação Ambiental. Vol. 20. Janeiro a Junho de 2008.

TAMAIO, I. A Mediação do professor na construção do conceito de natureza. Campinas, 2000.Dissert.(Mestr.) FE/Unicamp.

TUTORIAL HagaQuê. Disponívem em : http://www.hagaque.cjb.net/Download Hagáquê. Acesso em: 10 maio de 2011. 